\title{
Dietary patterns and asthma in the E3N
}

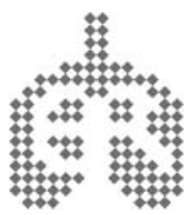
study

\author{
R. Varraso*,\#, F. Kauffmann*,\#, B. Leynaert", N. Le Moual*,\#, \\ M.C. Boutron-Ruault ${ }^{\#,+, \S}$, F. Clavel-Chapelon ${ }^{\#,+,}$ and I. Romieu ${ }^{+, f}$
}

ABSTRACT: The aim of the present study was to determine dietary patterns and investigate their association with asthma incidence, current asthma and frequent asthma exacerbations.

Dietary habits and asthma data were collected from the large E3N study (of French females, mostly teachers). Of the 54,672 females followed-up in $2003,2,634$ reported ever-adulthood asthma, 1,063 reported current asthma, 206 reported frequent asthma attacks (one or more a week), and 628 reported asthma onset between 1993 and 2003. Using principal component analysis, three dietary patterns were identified: the "prudent" pattern (fruits and vegetables); the "Western" pattern (pizza/salty pies, dessert and cured meats); and the "nuts and wine" pattern Pattern scores were categorised into tertiles, and the incidence and prevalence of asthma was compared between tertiles.

After adjustment for confounders, no association of dietary patterns was observed with asthma incidence, ever-asthma or current asthma. The Western pattern was associated with an increased risk of reporting frequent asthma attacks (highest versus lowest tertile odds ratio (OR) 1.79, 95\% confidence interval (Cl) 1.11-3.73). Increasing scores of the nuts and wine pattern were associated with a decreased risk of reporting frequent asthma attacks (highest versus lowest tertile OR 0.65, 95\% $\mathrm{Cl} 0.31-0.96$ ).

The results of the present study suggest that overall diet could be involved in frequent asthma exacerbations, one aspect of asthma severity.

KEYWORDS: Adults, asthma, asthma attacks, asthma incidence, diet, females

tudying dietary patterns instead of specific foods or nutrients is a new approach in nutritional epidemiology to assessing the effects of overall diet [1]. Usually determined by factor analysis, dietary patterns have been used to investigate the role of diet in several chronic diseases [2-5] but rarely in respiratory diseases [6-8]. Studies on the association of individual foods and nutrients and asthma are inconclusive $[9,10]$; an overall approach based on dietary patterns could provide some insight into the combination of foods that might be beneficial or detrimental to asthma prevalence and severity.

Recently, an association between dietary patterns and newly diagnosed chronic obstructive pulmonary disease (COPD) was reported in a large cohort of males and females in the USA [7,8]. A "prudent" pattern (high intake of fruits, vegetables, fish and whole grain products) was associated with a decreased risk, whereas a "Western" pattern (high intake of refined grains, cured and red meats, desserts and French fries) was associated with an increased risk. In contrast, no clear association was observed between dietary patterns and the risk of asthma onset in the two cohorts. However, the severity of asthma was not investigated. Furthermore, these studies were conducted in the USA and cultural factors, varying between country, influence behaviour and attitudes regarding food choices.

The purpose of the present study was to determine dietary patterns in a large population of French females and to investigate the relationship of these patterns with asthma prevalence and incidence in adulthood, and with frequent asthma attacks, an important component of asthma severity.

\section{MATERIALS AND METHODS}

\section{Study population}

The E3N study is a prospective investigation of major chronic diseases among members of the Mutuelle Générale de l'Education Nationale, a French national health insurance plan covering mostly teachers [11]. Briefly, half a million females aged 40-65 yrs in 1990, residing in continental France and insured by the Mutuelle Générale de 1'Education Nationale, were invited to participate. In total, $20 \%$ agreed to participate by filling in the first questionnaire and the

\section{AFFILIATIONS}

*INSERM, U780, Epidemiology and

Biostatistics

${ }^{+}$INSERM, ERI20,

\#Univ Paris-Sud, IFR69, and

${ }^{\S}$ Institut Gustave Roussy, Villejuif, and "INSERM, U700, Paris, France.

f Instituto Nacional de Salud Publica, Cuernavaca, Morelos, Mexico.

\section{CORRESPONDENCE}

I. Romieu, Instituto Nacional de Salud Publica, 655 Avenida Universidad

Col. Santa Maria Ahuacatitlán, 62508 , Cuernavaca, Morelos, Mexico. Fax: 527773111148

E-mail: iromieu@correo.insp.mx

Received:

October 042007

Accepted after revision:

September 152008

SUPPORT STATEMENT

The E3N study is supported by the Mutuelle Générale de l'Education Nationale (MGEN), the European Community, the French League against Cancer (LNCC), the Gustave Roussy Institute (IGR), the National Institute for Health and Medical Research (Inserm), the 3M Company and General Councils of France. I. Romieu was supported by the National Center for Environmental Health - Centers for Disease Control and Prevention (Atlanta GA, USA), the $\mathrm{GA}^{2} \mathrm{LEN}$ project (EU contract F00DCT-2004-506378) and the Spanish Ministry of Education and Science, SAB2004-0192. This project was supported by a grant from the Comité National contre les Maladies Respiratoires (Paris, France).

STATEMENT OF INTEREST

None declared. 
consent form. Females included were fairly representative of the population covered by the health insurance plan regarding age and geographic region. The general characteristics of this population have been reported elsewhere [11]. In brief, the mean age of the females was 48.9 yrs, they were well educated ( $>80 \%$ completed secondary school) and two thirds of them were never-smokers. Follow-up questionnaires were sent every 2 yrs after study commencement. In 1993, a validated dietary history questionnaire was sent to the participants [12]. This questionnaire also included a simple question regarding asthma. More detailed questions were included in the followup questionnaire administered in 2003 [13]. Part of the E3N cohort is also included in the European Prospective Investigation on Cancer (EPIC). Both dietary questionnaires and detailed asthma data were available for 56,881 females.

\section{Asthma assessment}

In 1993, asthma status was assessed using the simple question: "Have you ever had asthma attacks?" The age at the first attack was also recorded. In 2003, asthma was defined as recommended by the American Thoracic Society (ATS) using the following questions: "Have you ever had asthma attacks?" and if yes, "Was this diagnosis confirmed by a doctor?" [13]. For asthmatic females, age at the first attack, current asthma (in the last 12 months), frequency of attacks in the last 12 months (one or more per day, one or more per week, one or more per month, less than one per month), and current use of inhaled steroids and/or inhaled bronchodilators at least three times a week were recorded in 2003. Frequent asthma attacks were defined by a report of at least one attack of asthma per week in the last 12 months, regardless of any medication. In addition, females were considered to have adult-onset asthma between 1993 and 2003 if they: 1) did not report asthma attacks ever in the baseline questionnaire; and 2) met the ATS criteria for asthma definition at follow-up, with a coherent reported age of asthma onset (time of first attack between 1993 and 2003). Questionnaires were self-completed and returned by mail; no lung function test was performed.

\section{Dietary patterns}

Dietary patterns were developed using factor analysis [1]. The factors were rotated using an orthogonal transformation to achieve simpler structure with greater interpretability. The number of factors to retain was determined using the diagram of eigenvalues, the Scree plot. Foods that loaded at $\geqslant 0.40$ were considered to be making a contribution to the factor, although the value for meaningful factor loading was arbitrary. The factor score for each pattern was constructed by summing up observed intakes of the component food items weighted by the factor loading. Food items were grouped a priori into 56 separate food groups (see Appendix) and dietary patterns were described using these food groups. To assess the sensitivity of dietary patterns due to the a priori grouping of foods, principal component analysis was also performed using the 208 food items.

\section{Assessment of other variables}

Total energy intake was estimated in 1993 using the diet questionnaire and expressed in $\mathrm{kcal} \cdot \mathrm{day}^{-1}$. Because the population of the present study was mostly composed of teachers, years of education were used as a proxy for socio-economic status. Hay fever-ever was classified as either present or absent. Dietary supplementation was investigated in 2003 (not available in 1993). Participants reported the use of calcium (15.5\%), fluoride $(1.0 \%)$, iron $(3.1 \%)$, magnesium $(15.2 \%)$, phyto-oestrogens (soy; $5.3 \%$ ), other minerals / trace elements $(9.9 \%)$, vitamin A $(3.9 \%)$, vitamin B (5.1\%), vitamin C $(7.6 \%)$, vitamin D $(6.0 \%)$, vitamin $\mathrm{E}(7.0 \%)$, folic acid $(1.0 \%)$, beta carotene $(3.1 \%)$ and other vitamins $(2.2 \%)$. Those taking supplements might be more likely to modify their diet in relation to their disease; in the E3N study, such participants have been found to have a different lifestyle and dietary habits compared to non-users [14, 15].

Body mass index (BMI), physical activity, smoking status and menopausal status were investigated in 1993 and in each follow-up questionnaire. BMI was calculated based on height and weight, and it was used as a continuous and categorical variable. Physical activity was measured in metabolic equivalents (METs) week $^{-1}$ [16]. Information on tobacco consumption included the categories never-, past, and current smoker. Participants were classified as pre-menopausal, post-menopausal or peri-menopausal.

\section{Statistical analysis}

Females with extreme values (in the bottom or top $1 \%$ ) of the ratio between energy intake and required energy (calculated after taking age, weight and height into account) were excluded $(n=1,009)$. Among asthmatic females $(n=3,834)$, 1,200 were excluded because they reported asthma diagnosis during childhood ( $\leqslant 16$ yrs of age) without current asthma. The present analysis is based on 54,672 females (2,634 with ever-asthma in adulthood and 52,038 nonasthmatics).

For the cross-sectional analysis, the associations between respiratory phenotypes and diet were investigated using logistic regression models, adjusting for potential confounding factors, including age, total energy intake, BMI, physical activity, smoking status, menopausal status, education and dietary supplementation. In order to assess the association between both dietary behaviour as a whole and nonsupplemented diet itself, analyses were performed in all females and in those who did not use supplements. Analyses were both adjusted and stratified for inhaled steroid use. Dietary patterns and food intake were categorised in tertiles. Odds ratios (ORs) were determined using the lowest tertile as the reference. For the longitudinal analysis, relative risk for asthma onset was estimated using Cox proportional hazards models, with age as the timescale. Potential confounding variables included BMI, physical activity, smoking status and menopausal status treated as time-dependent variables, and total energy intake, dietary supplementation and education.

\section{RESULTS}

\section{Assessment of dietary patterns}

Three major dietary patterns were identified (table 1). The first factor was loaded heavily with fruits and vegetables; the second factor was loaded heavily with pizza/salty pies, dessert, cured meats and pasta; and the third factor was loaded heavily with nuts and seeds, salty biscuits, olives, wine, and fortified wine (see Appendix). The three factors were labelled as the "prudent", "Western", and "nuts and wine" patterns, respectively. The principal component analysis 


\begin{tabular}{|c|c|c|c|}
\hline & $\begin{array}{c}\text { Factor 1: } \\
\text { prudent } \\
\text { pattern }\end{array}$ & $\begin{array}{c}\text { Factor 2: } \\
\text { Western } \\
\text { pattern }\end{array}$ & $\begin{array}{c}\text { Factor 3: } \\
\text { nuts and } \\
\text { wine pattern }\end{array}$ \\
\hline Fruity vegetables & 0.89 & & \\
\hline Root vegetables & 0.85 & & \\
\hline Cabbages & 0.79 & & \\
\hline Mushrooms & 0.73 & & \\
\hline Grain and peas & 0.72 & & \\
\hline $\begin{array}{l}\text { Leafy vegetables (except } \\
\text { cabbages) }\end{array}$ & 0.71 & & \\
\hline Stalk vegetables & 0.70 & & \\
\hline Fruits with beta carotene & 0.61 & & \\
\hline Fruits with citric & 0.60 & & \\
\hline Condiments and sauces & 0.42 & 0.32 & \\
\hline Red meat & 0.34 & & \\
\hline Poultry & 0.33 & & \\
\hline Blue fish & 0.32 & & \\
\hline Onions, garlic & & 0.73 & \\
\hline Dough and pastry & & 0.70 & \\
\hline Cream desserts & & 0.62 & \\
\hline Ice cream & & 0.60 & \\
\hline Processed meats & & 0.55 & 0.33 \\
\hline Cakes, pies and pastries & & 0.45 & \\
\hline Pasta, rice and grain & & 0.40 & \\
\hline Potatoes and other tubers & & 0.31 & \\
\hline Egg & & 0.30 & \\
\hline Nuts and seeds & & & 0.58 \\
\hline Salty biscuits, aperitif biscuits & & & 0.56 \\
\hline Wine & & & 0.48 \\
\hline Olives & & & 0.45 \\
\hline Fortified wines & & & 0.40 \\
\hline Cocktails, punches & & & 0.36 \\
\hline Crustaceans, molluscs & & & 0.35 \\
\hline Spirits & & & 0.35 \\
\hline
\end{tabular}

Diet was assessed in 1993; $n=54,672$. Factor loadings represent the correlation between factor scores and intake of food groups. Foods or food groups with factor loadings $<0.30$ for both factors were excluded. Absolute values $<0.30$ were not listed in the table for simplicity. Factor loadings presented are those resulting from orthogonal rotation. By construction, the dietary patterns were independent and females with a high score for the nuts and wine pattern could also have a high score on the prudent and/or Western pattern. In this analysis, $10.9 \%$ of the females were in the highest tertile both for the prudent and the Western diet, $11.5 \%$ were in the highest tertile both for the "prudent" and the "nuts and wine" pattern and $12.5 \%$ were in the highest tertile both for the "Western" and the "nuts and wine" pattern.

performed on the 208 foods without a priori grouping gave similar results.

\section{Dietary patterns and asthma prevalence and incidence in adulthood}

Among the 2,634 females reporting asthma-ever in adulthood, 1,063 (40.5\%) reported current asthma at follow-up, of whom 206 $(19.4 \%)$ had experienced frequent attacks. Current asthmatics

\begin{tabular}{|c|c|c|c|}
\hline \multirow[t]{2}{*}{ TABLE 2} & \multicolumn{2}{|c|}{$\begin{array}{l}\text { s (recorded in 2003) } \\
\text { to current asthma }\end{array}$} & \multirow[b]{2}{*}{$p$-value ${ }^{+}$} \\
\hline & $\begin{array}{l}\text { Current } \\
\text { asthma }^{\#}\end{array}$ & $\begin{array}{c}\text { No } \\
\text { asthma }\end{array}$ & \\
\hline Age yrs & $52.5 \pm 6.5$ & $52.7 \pm 6.5$ & 0.3 \\
\hline Caloric intake kcal $\cdot$ day $^{-1}$ & $2190 \pm 602$ & $2176 \pm 569$ & 0.4 \\
\hline Physical activity METs. week $^{-1}$ & $45.8 \pm 30.0$ & $46.4 \pm 30.2$ & 0.6 \\
\hline $\mathrm{BMI} \mathbf{k g} \cdot \mathrm{m}^{2}$ & $24.8 \pm 4.6$ & $23.8 \pm 3.6$ & $<0.001$ \\
\hline \multicolumn{4}{|l|}{$\mathrm{BMI} \mathbf{k g} \cdot \mathrm{m}^{2}$} \\
\hline$<20$ & 9.7 & 11.5 & \\
\hline 20-24.9 & 49.2 & 58.5 & $<0.001$ \\
\hline $25-29.9$ & 29.5 & 24.0 & \\
\hline$\geqslant 30$ & 11.6 & 6.0 & \\
\hline \multicolumn{4}{|l|}{ Tobacco consumption } \\
\hline Never-smokers & 51.3 & 56.4 & \\
\hline Ex-smokers & 38.6 & 34.0 & 0.003 \\
\hline Current smokers & 10.1 & 9.6 & \\
\hline \multicolumn{4}{|l|}{ Menopausal status } \\
\hline Pre-menopause & 5.6 & 4.6 & \\
\hline Post-menopause & 94.4 & 95.3 & 0.3 \\
\hline Peri-menopause & 0.0 & 0.1 & \\
\hline \multicolumn{4}{|l|}{ Education number of school yrs } \\
\hline$\leqslant 12$ & 11.7 & 10.7 & \\
\hline 14 & 48.3 & 51.9 & 0.15 \\
\hline 16 & 20.4 & 19.0 & \\
\hline 17 & 19.6 & 18.4 & \\
\hline Multivitamin supplement use ${ }^{\S}$ & 43.0 & 37.2 & $<0.001$ \\
\hline Hay fever-ever & 27.8 & 5.1 & $<0.001$ \\
\hline Bronchodilator use & 48.3 & 0.8 & $<0.001$ \\
\hline Inhaled steroid use & 31.9 & 1.2 & $<0.001$ \\
\hline
\end{tabular}

Data are presented as mean \pm SD or $\%$, unless otherwise stated. METs: metabolic equivalents; BMI: body mass index. ${ }^{\#}: \mathrm{n}=1,063 ;{ }^{\bullet}: \mathrm{n}=52,038$; $^{+}$: $\mathrm{t}-$ tests were used for continuous variables and Chi-squared tests were used for categorical variables; ${ }^{\text {s: }}$ recorded in 2003 and includes calcium, fluorine, iron magnesium, phyto-oestrogens (soy), other minerals/trace elements, vitamins A $\mathrm{B}, \mathrm{C}, \mathrm{D}$ and $\mathrm{E}$, folic acid, beta carotene, other vitamins.

(1,063 females) had a larger BMI, were more often ex-smokers, reported hay fever more often, and more frequently used dietary supplements than nonasthmatics (table 2).

Females taking supplements $(n=20,203)$ were significantly older (mean \pm SD age of $53.3 \pm 6.7$ versus $52.3 \pm 6.4 \mathrm{yrs}$ ), more physically active $\left(40.1 \pm 25.6\right.$ versus $38.8 \pm 25.7$ METs' week $\left.^{-1}\right)$ and reported a higher BMI $\left(23.0 \pm 3.2\right.$ versus $\left.22.4 \pm 2.9 \mathrm{~kg} \cdot \mathrm{m}^{2}\right)$ than those without supplement intake $(n=33,263)$. Females who took supplements also reported more hay fever (16.6 versus $12.1 \%$ ) and ever-asthma (5.3 versus $4.5 \%$ ), and ate more fruit, vegetables, fish and olive oil, and less processed meats and desserts than females without supplement intake. Similar results were found after adjustment for age.

No statistically significant association was found between dietary patterns and adulthood ever-asthma among all females and among females without supplement intake (data not shown). Similarly, no association was found between dietary patterns and current asthma (table 3). 


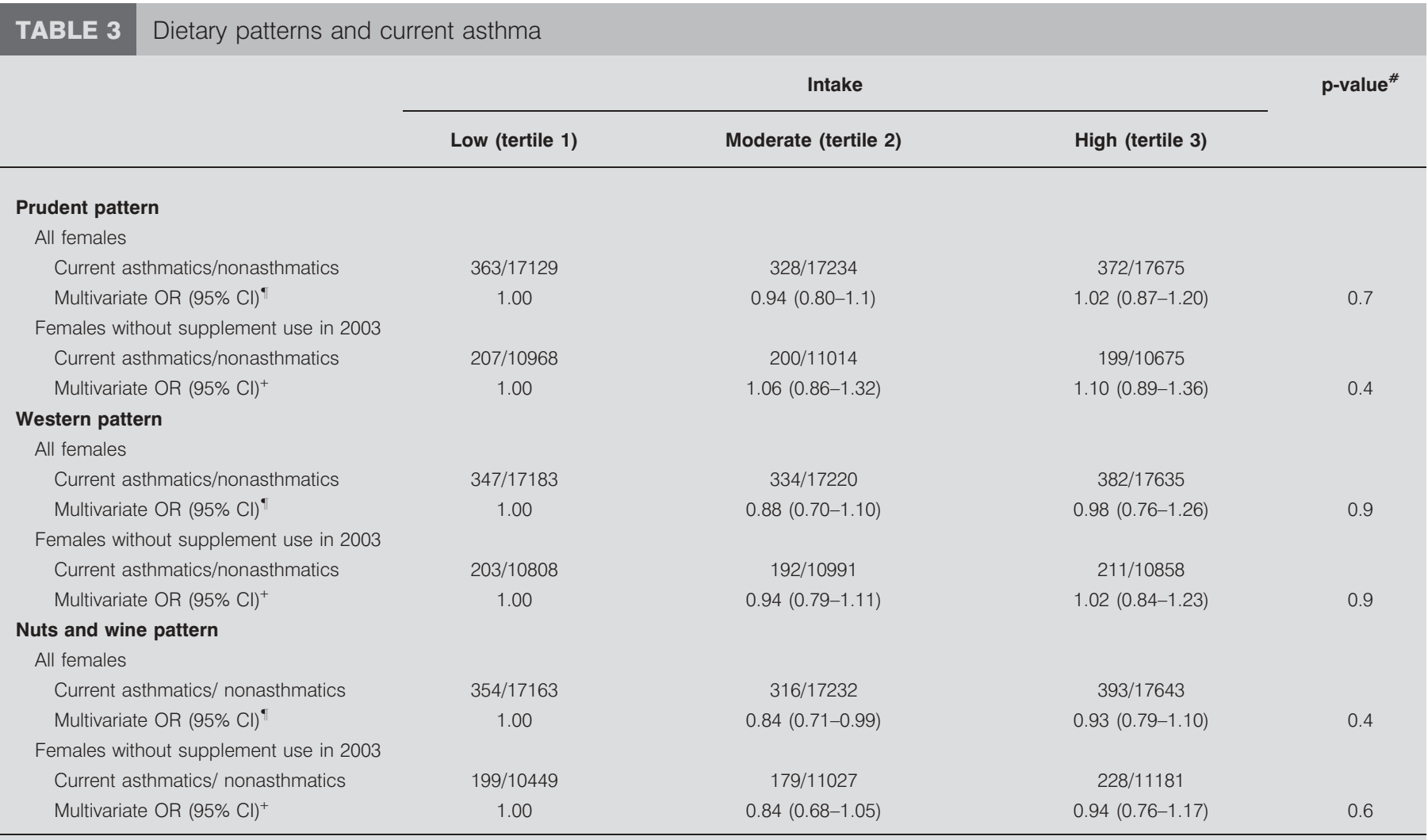

Data are presented as $n$, unless otherwise stated. The reference category is based on the lowest category of intake. Diet was assessed in 1993 and current asthma was assessed in 2003.OR: odds ratio; Cl: confidence interval. ${ }^{*}$ : for trend. Based on each intake category and modelling these as continuous variables in a logistic regression. $\because$ : logistic regressions adjusted for age, caloric intake, body mass index (BMI), tobacco consumption, physical activity, menopausal status, education and multivitamin supplement use. ${ }^{+}$: logistic regressions adjusted for age, caloric intake, BMI, tobacco consumption, physical activity, education and menopausal status. $\mathrm{n}=53,101$.

The only respiratory phenotype that we were able to analyse prospectively in this cohort was ever asthma. Between 1993 and 2003, we identified 628 incident cases of asthma. No relationship between dietary patterns and the risk of adultonset asthma was observed, either among all females or among females without supplement intake (table 4).

\section{Dietary pattern and the frequency of asthma attacks}

Among all current asthmatics, those reporting at least one asthma attack per week were significantly older (mean \pm SD age of $54.5 \pm 6.9$ versus $51.8 \pm 6.3$ yrs; $\mathrm{p}<0.001$ ) and had a higher education level than asthmatics with less than one attack per week, even after adjustment for age. Among females with at least one attack per week $(n=206), 45 \%$ used inhaled steroids compared with $28.5 \%$ of those with less than one attack per week $(n=786)$. Among current asthmatics, the use of multivitamin supplements was similar in females with at least one attack per week to those with less than one attack per week (42.7 and $43.2 \%$, respectively).

The nuts and wine pattern was negatively and significantly associated with the risk of frequent asthma attacks both among all current asthmatics $(p=0.01)$ and in the subgroup of nonsupplement users $(p=0.03$; table 5$)$. The risk of frequent asthma attacks increased significantly over each tertile of the Western pattern only among asthmatics without supplement intake $(p=0.02)$. No association was found between the prudent pattern and frequent asthma attacks in females both with and without supplement intake. Further adjustment for inhaled steroids did not modify the results. After further stratification according to the use of inhaled steroids, similar results were found among females both with and without current use of inhaled steroids.

Due to the potential overlap between the diagnosis of COPD and asthma, analyses restricted to never-smokers were also performed. Among never-smokers, the nuts and wine pattern remained negatively and significantly associated with the risk of frequent asthma attacks (highest versus lowest tertile OR $0.49,95 \%$ CI $0.25-0.98 ; p=0.02)$. In never-smoker asthmatics without supplement intake, a borderline significant association was found between the Western diet and the risk of frequent asthma attacks (highest versus lowest tertile OR 2.36, 95\% CI 0.89-6.26; $\mathrm{p}=0.07)$.

\section{Intake of individual foods and the frequency of asthma attacks}

The five individual foods or food groups with the highest loading factor for the nuts and wine and for the Western patterns were studied to determine their association with the frequency of asthma attacks.

Of the five individual foods or food groups with the highest loading factor for the nuts and wine pattern (nuts and seeds, 
TABLE 4 Dietary patterns and adult-onset asthma

\begin{tabular}{|c|c|c|c|c|}
\hline & \multicolumn{3}{|c|}{ Intake } & \multirow[t]{2}{*}{ p-value ${ }^{\#}$} \\
\hline & Low (tertile 1) & Moderate (tertile 2) & High (tertile 3) & \\
\hline \multicolumn{5}{|l|}{ Prudent pattern } \\
\hline \multicolumn{5}{|l|}{ All females } \\
\hline Asthma incidence/at risk & 208/17301 & $202 / 17405$ & 218/17332 & \\
\hline Asthma incidence/at risk & $131 / 10968$ & $124 / 11014$ & $136 / 10675$ & \\
\hline Multivariate RR $(95 \% \mathrm{Cl})^{+}$ & 1.00 & $0.96(0.75-1.22)$ & $0.98(0.78-1.24)$ & 0.9 \\
\hline \multicolumn{5}{|l|}{ Western pattern } \\
\hline \multicolumn{5}{|l|}{ All females } \\
\hline Asthma incidence/at risk & $223 / 17354$ & $182 / 17387$ & 223/17297 & \\
\hline Multivariate RR $(95 \% \mathrm{Cl})^{\bullet}$ & 1.00 & $0.86(0.62-1.14)$ & $0.95(0.77-1.26)$ & 0.4 \\
\hline \multicolumn{5}{|l|}{ Nuts and wine pattern } \\
\hline \multicolumn{5}{|l|}{ All females } \\
\hline Asthma incidence/at risk & $189 / 17337$ & $201 / 17406$ & 238/17295 & \\
\hline Multivariate RR $(95 \% \mathrm{Cl})^{\bullet}$ & 1.00 & $0.96(0.78-1.17)$ & $1.01(0.82-1.23)$ & 0.9 \\
\hline \multicolumn{5}{|c|}{ Females without supplement use in 2003} \\
\hline Asthma incidence/at risk & $118 / 10449$ & $125 / 11027$ & $148 / 11181$ & \\
\hline Multivariate $\mathrm{RR}(95 \% \mathrm{Cl})^{+}$ & 1.00 & $0.92(0.72-1.19)$ & $0.98(0.75-1.26)$ & 0.9 \\
\hline
\end{tabular}

Data are presented as $n$, unless otherwise stated. The reference category is based on the lowest category of intake. Diet was assessed in 1993 and adult onset was assessed between 1993 and 2003. RR: relative risk; Cl: confidence interval. ${ }^{*}$ : for trend. Based on each intake category and modelling these as continuous variables in a Cox model. ': Cox models adjusted for caloric intake, body mass index (BMI), tobacco consumption, physical activity, menopausal status, education and multivitamin supplements use. ${ }^{+}$: Cox models adjusted for caloric intake, BMI, tobacco consumption, physical activity, education and menopausal status. $n=52,666$.

salty biscuits/aperitif biscuits, wine, olives and fortified wines), the risk of frequent attacks was lower in females with the highest consumption of nuts and seeds $\left(>5.3 \mathrm{~g} \cdot \mathrm{day}^{-1}\right)$ than in females with the lowest consumption $\left(\leqslant 1.0 \mathrm{~g} \cdot \mathrm{day}^{-1}\right)$, both in all current asthmatics (highest versus lowest tertile OR 0.64, 95\% CI $0.41-0.99 ; \mathrm{p}=0.03$ ) and in current asthmatics without supplement intake (highest versus lowest tertile OR 0.55, 95\% CI 0.30$1.01 ; \mathrm{p}=0.04)$. Among current asthmatics, the risk of frequent asthma attacks was lower among females with the highest consumption of wine $\left(>89.4 \mathrm{~g} \cdot \mathrm{day}^{-1}\right)$ than in females with the lowest consumption $\left(\leqslant 13.6 \mathrm{~g} \cdot \mathrm{day}^{-1}\right.$; highest versus lowest tertile OR 0.60 , 95\% CI 0.38-0.94; $\mathrm{p}=0.05)$. No association was observed for the other food groups of this pattern.

Of the five individual foods or food groups with the highest loading factor for the Western pattern (onion/garlic, dough and pastry, cream desserts, ice cream and processed meats), no specific food was associated with frequent asthma attacks.

\section{DISCUSSION}

Three distinct dietary patterns were identified in a large cohort of French adult females: a prudent pattern; a Western pattern; and a nuts and wine pattern. No association was observed between these dietary patterns and adult-onset asthma, ever-asthma in adulthood or current asthma. In contrast, significant associations were observed with the frequency of asthma attacks. The highest tertile of the nuts and wine pattern was associated with a decreased risk of frequent asthma attacks in asthmatic females. The highest tertile of the Western pattern was associated with an increased risk of frequent asthma attacks only among asthmatic females without supplement intake. No association was observed with the prudent pattern.

Similar dietary patterns have been identified in other populations [2-4, 6, 17]. There is a consistency across studies to identify a prudent pattern and a Western pattern, whereas the "drinker" pattern was mostly identified in European surveys $[3,17]$. In a recent study, with different food groups and a larger sample of the E3N cohort, four dietary patterns close to those of the present study were identified: "healthy" (vegetables, fruit, yoghurt, sea products and olive oil); "Western" (potatoes, pizzas/pies, sandwiches, sweets, cakes, cheese, cereal products, processed meat, eggs and butter); "drinker" (sandwiches, snacks, processed meat and alcoholic beverages); and "meat eaters" (meat, poultry and margarine) [18].

Only three recent studies used dietary patterns to assess diet in relation to respiratory phenotypes [6-8]. The present results regarding adult-onset asthma are consistent with these studies. No significant association between dietary patterns and asthma incidence was observed in 52,325 male and female adult Chinese Singaporeans, aged $45-74$ yrs [6]. Two patterns were evidenced in this cohort: a "vegetable, fruit, soy" pattern and a "meat-dim sum" pattern (chicken, pork, fish, rice and 
TABLE 5 Dietary patterns and frequent asthma attacks in asthmatic females

Intake

p-value ${ }^{\#}$

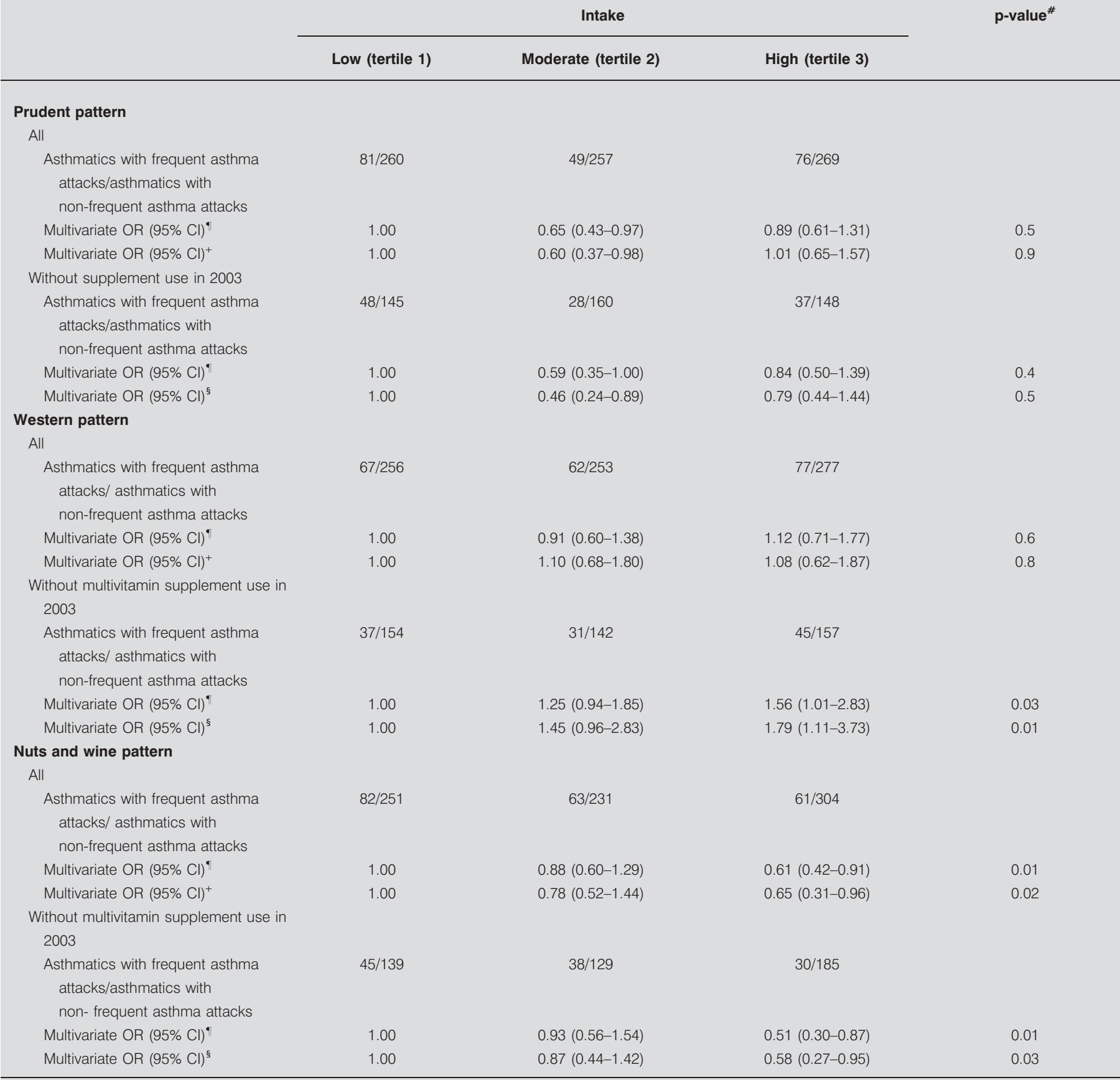

Data are presented as n, unless otherwise stated. The reference category is based on the lowest category of intake. Diet was assessed in 1993 and the frequency of asthma attacks was assessed in 2003. Among the 992 current asthmatics assessed, 206 had frequent asthma attacks and 786 had no frequent asthma attacks. OR: odds ratio; Cl: confidence interval. ${ }^{*}$ : for trend. Based on each intake category and modelling these as continuous variables in a logistic regression. ": logistic regressions adjusted for age, caloric intake and body mass index (BMI). ${ }^{+}$: logistic regressions adjusted for age, caloric intake, BMl, tobacco consumption, physical activity, menopausal status, education and multivitamin supplements use. ${ }^{\text {s: }}$ logistic regressions adjusted for age, caloric intake, BMI, tobacco consumption, physical activity, education and menopausal status.

noodle dishes, and preserved foods). In the USA, no association was reported between the risk of adult-onset asthma and dietary patterns in 42,917 males aged $40-75$ yrs from the Health Professionals Follow-up Study (HPFS) [7]. In 72,043 US females aged 30-55 yrs from the Nurses' Health Study (NHS), the Western pattern was not associated with adult-onset asthma but a borderline and positive association was reported between the prudent diet and adult-onset asthma [8]. To the 
present authors' knowledge, the current study is the first to observe a relationship between a Western diet and the risk of frequent asthma attacks. In the study among the Chinese Singaporeans, the meat-dim sum pattern was associated with an increased risk of incident cough with phlegm, and both in the NHS [8] and in the HPFS [7], the Western pattern was associated with an increase of COPD. No association was found between dietary patterns and the prevalence and incidence of asthma in the present study. Therefore, one may wonder whether the same mechanisms as those underlying the association between diet and COPD could also be involved in the association between diet and asthma severity, whereas dietary factors would act differently on the risk of asthma onset. Previous studies have mostly focused on the potentially protective effects of antioxidants [10]; recently, however, both in a longitudinal survey [19] and a cross-sectional survey involving forced expiratory volume in one second measurement [20], it was reported that frequent consumption of cured meats was associated with higher prevalence and incidence of COPD. In the present study, no specific food from the Western pattern was associated with frequent asthma attacks, suggesting the deleterious role of the overall diet rather than of one specific food. In the NHS, the Western pattern, which is similar to that of the present study, was positively correlated with concentrations of C-reactive protein and interleukin-6, two markers of systemic inflammation [21]. Further studies are needed to better understand the association between Western diet, inflammation and asthma severity.

The present results also demonstrate an inverse association between the nuts and wine pattern and the frequency of asthma attacks. Regarding the specific foods from this pattern, an inverse association was reported between frequent asthma attacks with both nuts/seeds and wine. It was considered that the negative association between nuts and seeds and asthma attacks might be explained by a protective effect of vitamin E. However, the contribution to the total vitamin E intake from nuts and seeds in this population was estimated to be only $3.3 \%$ (the fifth highest contribution of the total vitamin E). The borderline significant negative association between moderate wine consumption and frequent asthma attacks observed in the present study is consistent with the inverse association of red wine intake with asthma severity assessed by a quality of life scale in an English population [22]. Wine is an important source of flavonoids, which could plausibly reduce asthma inflammation through antioxidant, antiallergic and antiinflammatory properties [23]. Besides flavonoids, alcohol itself may have a modest bronchodilator effect and is likely to relax bronchial smooth muscle [24]. Nevertheless, reverse causation cannot be excluded. Sensitised asthmatics might avoid the intake of nuts as well as the intake of wine, alcoholic drinks and especially red wine, being perceived by a large number of asthmatics to trigger their asthma [24]. Replication of the present findings in studies with information on potential nuts and wine avoidance is warranted to support the hypothesis of a protective effect in asthma. In the present study, the effect of diet was stronger amongst females without supplement intake. It is possible that vitamin/mineral supplementation masks the effect of foods or that adjustment for supplement intake could not adequately control for differences in lifestyle and other characteristics of females using supplements.
Dietary patterns have several advantages over focusing on nutrients and foods to assess the association between diet and disease, particularly for diseases like asthma, for which no individual dietary factor has shown any consistent and strong effect. The factor analysis approach involves several arbitrary decisions, including the construction of the food groups, the number of factors to extract and the method of rotation, and even the labelling of the components [1]. The present authors also performed a principal component analysis with individual foods and beverages, without grouping them a priori. This sensitivity analysis showed a high consistency and reproducibility of the patterns.

Distinction between asthma and COPD in the elderly is not easy. In the E3N study, asthma was only assessed by questionnaire, and self-reported asthma might have included COPD. Therefore, the present authors conducted an analysis restricted to never-smokers, who are unlikely to have COPD. Results remained similar, supporting the hypothesis that dietary patterns relate to the frequency of asthma attacks. The severity of asthma is difficult to assess in epidemiological studies [25] and there is now a general consensus emerging that asthma is unlikely to be a single disease but different overlapping phenotypes [26]. It was recently shown that quantitative scores combining clinical items and treatment had good ability to detect risk factors by reducing misclassification of the disease status [27, 28]. The new Global Initiative for Asthma (GINA) recommendations have evolved from severity to control and underlined the importance of asthma treatment [29]. Furthermore, it was recently recommended that asthma severity should no longer be used for clinical features off-treatment [30]. In the $\mathrm{E} 3 \mathrm{~N}$ study, few data regarding treatment were available; it was therefore not possible to build a reliable score combining both frequency of asthma attacks and treatment. However, further adjustment and even stratification regarding the use of inhaled steroids did not modify the present findings.

For current asthma and frequent asthma attacks, the crosssectional nature of the analysis limits interpretation, given that females with asthma might have modified their dietary pattern towards a healthier pattern or have avoided some foods because of their symptoms. However, the longitudinal findings of the present study for adulthood asthma were similar to the cross-sectional findings. Furthermore, longitudinal studies performed in cohorts of adults have shown reasonable tracking of diet [31], and a reproducibility and validity of the major dietary patterns defined by factor analysis with data from an food frequency questionnaire has been reported over 8 yrs [32]. Regarding the generalisation of the present findings, caution is required as females from the E3N study might be more health-conscious than the general population (i.e. fewer smokers, with a higher intake of fruits and vegetables, more physically active). Confirmation of these findings in other populations, particularly among males, is warranted.

In summary, the present study reports that in French females the Western pattern was positively associated with frequent asthma attacks, while the nuts and wine pattern was negatively associated with frequent asthma attacks. Further studies are needed to improve the understanding of the complex association between diet and asthma. 


\section{APPENDIX}

Food groupings for factor analysis

Foods or food groups $\quad$ Food items

\begin{tabular}{|c|c|}
\hline $\begin{array}{l}\text { Potatoes and other } \\
\text { tubers }\end{array}$ & $\begin{array}{l}\text { Potato salad, potatoes deep fried, smashed } \\
\text { potatoes }\end{array}$ \\
\hline $\begin{array}{l}\text { Leafy vegetables } \\
\text { (except cabbages) }\end{array}$ & $\begin{array}{l}\text { Green salad, endives as salad, chicory, } \\
\text { spinach }\end{array}$ \\
\hline Fruiting vegetables & $\begin{array}{l}\text { Artichoke, tomatoes as salad, avocado, } \\
\text { cucumber, tomato (pizza, salty pie, salty } \\
\text { pancake), cooked tomatoes, green beans, } \\
\text { aubergine, bell pepper, courgette }\end{array}$ \\
\hline Root vegetables & $\begin{array}{l}\text { Grated carrots, radish, beetroot, celeriac, } \\
\text { cooked carrots, salsify }\end{array}$ \\
\hline Cabbages & $\begin{array}{l}\text { Cauliflower as salad, white or red cabbage raw, } \\
\text { Brussels sprouts, cauliflower, cabbage }\end{array}$ \\
\hline Mushrooms & $\begin{array}{l}\text { Mushrooms (pizza, salty pie, salty pancake), } \\
\text { mushrooms }\end{array}$ \\
\hline Grain and pod vegetables & Maize as salad, peas \\
\hline Onion, garlic & $\begin{array}{l}\text { Onions (pizza, salty pie, salty pancake), onions } \\
\text { (sandwich, hamburger) }\end{array}$ \\
\hline Stalk vegetables & $\begin{array}{l}\text { Leek as salad, leek (pizza, salty pie, salty } \\
\text { pancake), celery, beet, fennel }\end{array}$ \\
\hline Legumes & Lentils as salad, legumes \\
\hline Fruits with citric & Orange, grapefruit, mandarin, kiwi \\
\hline Fruits with beta carotene & Peach, melon, apricot \\
\hline Other fruits & $\begin{array}{l}\text { Fresh fruits unspecified, apple, pear, banana, } \\
\text { pineapple, strawberries or raspberries, cherries, } \\
\text { raisins, plums, compote fruits, fruits on syrup }\end{array}$ \\
\hline Nuts and seeds & Nuts and seeds \\
\hline Olives & Olives \\
\hline Milk & $\begin{array}{l}\text { Milk nonspecified, whole milk, skimmed milk, } \\
\text { semi-skimmed milk, sweetened } \\
\text { concentrated milk }\end{array}$ \\
\hline Milk beverages & Chocolate drink \\
\hline Yoghurts & $\begin{array}{l}\text { Yoghurt, ordinary yoghurt, ordinary yoghurt } 0 \% \text { fat, } \\
\text { ordinary yoghurt sweetened, flavoured yoghurt, } \\
\text { flavoured yoghurt } 0 \% \text { fat, flavoured yoghurt light }\end{array}$ \\
\hline Cottage cheese & $\begin{array}{l}\text { Cottage cheese, ordinary cottage cheese, cottage } \\
\text { cheese } 0 \% \text { fat, cottage cheese } 10-20 \% \text { fat, } \\
\text { cottage cheese } 30-40 \% \text { fat, flavoured cottage } \\
\text { cheese } 0 \% \text { fat, flavoured cottage cheese } 10 \text { - } \\
20 \% \text { fat, flavoured cottage cheese } 30-40 \% \text { fat }\end{array}$ \\
\hline Cheese & $\begin{array}{l}\text { Nonspecified cheese, camembert, St Marcellin, } \\
\text { Brie, munster, soft cheeses, blue cheese, } \\
\text { Gruyere, Cantal, Goat cheeses, other cheeses, } \\
\text { low-fat cheeses, mozzarella (pizza, salty pie, } \\
\text { salty pancake), gruyere (pizza, salty pie, salty } \\
\text { pancake), gruyere (sandwich, hamburger) }\end{array}$ \\
\hline Cream desserts & Cream dessert, cream dessert with rice \\
\hline Cream & $\begin{array}{l}\text { Sour cream (pizza, salty pie, salty pancake), } \\
\text { plain sour cream, sour cream ( } 15 \% \text { fat) }\end{array}$ \\
\hline Pasta, rice, grain & $\begin{array}{l}\text { Pasta, couscous, rice nonspecified, normal rice, } \\
\text { whole rice }\end{array}$ \\
\hline Bread & $\begin{array}{l}\text { Nonspecified bread, white bread, bread whole } \\
\text { flour, white bread slices, biscotti, unleavened } \\
\text { bread, crackers, toasted bread, Wasa bread, } \\
\text { small toasted bread, hamburger bread, white } \\
\text { bread (sandwich, hamburger) }\end{array}$ \\
\hline
\end{tabular}

\begin{tabular}{|c|c|}
\hline Foods or food groups & Food items \\
\hline Breakfast cereals & Breakfast cereals \\
\hline $\begin{array}{l}\text { Salty biscuits, } \\
\text { aperitif biscuits }\end{array}$ & Salted biscuits \\
\hline Dough and pastry & Pizza dough, puff pastry \\
\hline Red meat & $\begin{array}{l}\text { Nonspecified red meats, beef, beef } 15 \% \text { fat } \\
\text { (sandwich, hamburger), pork, lamb, veal, } \\
\text { horse }\end{array}$ \\
\hline Poultry & Poultry, rabbit \\
\hline Processed meats & $\begin{array}{l}\text { Sausage, pate, potted meat, cooked ham } \\
\text { (pizza, salty pie, salty pancake), smoked lard } \\
\text { (pizza, salty pie, salty pancake), sausages, } \\
\text { blood sausage, andouillette, cooked ham } \\
\text { (hamburger, sandwich) }\end{array}$ \\
\hline Offal & Liver, other offal \\
\hline Crustaceans, molluscs & Sea fruits \\
\hline Blue fish & $\begin{array}{l}\text { Canned fish, fresh sardines, mackerel fresh, } \\
\text { fresh salmon }\end{array}$ \\
\hline Whitefish & $\begin{array}{l}\text { Fish nonspecified, hake, julienne, dab, haddock } \\
\text { sole, pollock, whiting, codfish, trout, other fish }\end{array}$ \\
\hline Egg & $\begin{array}{l}\text { Boiled eggs, fried eggs, scrambled eggs, egg } \\
\text { (pizza, salty pie, salty pancake) }\end{array}$ \\
\hline Vegetable oils & Peanut oil, sunflower oil, olive oil, corn oil \\
\hline Butter & Butter, low-fat butter \\
\hline Margarines & Normal margarine, low-fat margarine \\
\hline Other animal fats & Duck fat, other fat \\
\hline Chocolate & Candy bars, chocolate bars \\
\hline Sweets & Sweets \\
\hline Ice cream & Ice cream \\
\hline Cakes, pies, pastries & $\begin{array}{l}\text { Croissant, brioche, cakes, pancake (pizza, salty } \\
\text { pie, salty pancake), cream cakes, fruit pie }\end{array}$ \\
\hline Dry cakes, biscuits & Dry biscuits \\
\hline Fruits juice & Fruits juice \\
\hline Carbonated/soft/isotonic & $\begin{array}{l}\text { Soft drinks, sweetened soft drinks, light soft } \\
\text { drinks }\end{array}$ \\
\hline Coffee and tea & Chicory, coffee, tea \\
\hline Waters & Tap water, mineral water, nonspecified water \\
\hline Wine & Wine or champagne \\
\hline Fortified wines & Muscat, porto, vermouth \\
\hline Beer, cider & Nonspecified beer, beer, special beer, cider \\
\hline Spirits & Whisky, gin, vodka, digestive \\
\hline Aniseed drinks & Alcohol with anis \\
\hline Cocktails, punches & $\begin{array}{l}\text { Punch, aperitif made of cassis liqueur and white } \\
\text { wine }\end{array}$ \\
\hline Condiments and sauces & $\begin{array}{l}\text { Mayonnaise, nonspecified salad dressing, } \\
\text { commercial plain salad dressing, commercial } \\
\text { low-fat salad dressing, home-made salad } \\
\text { dressing with peanut oil, home-made salad } \\
\text { dressing with olive oil, home-made salad } \\
\text { dressing with corn oil, home-made salad } \\
\text { dressing with sunflower oil, home-made salad } \\
\text { dressing with cole seed oil, home-made salad } \\
\text { dressing with soybean oil, béchamel sauce } \\
\text { (pizza, salty pie, salty pancake), ketchup } \\
\text { (sandwich, hamburger), béchamel sauce } \\
\text { (sandwich, hamburger) }\end{array}$ \\
\hline Soups & Soups \\
\hline
\end{tabular}




\section{ACKNOWLEDGEMENTS}

The present authors would like to thank all the participants of the E3N study and A. Fabre, L. Hoang, M. Niravong and M. Fangon (all INSERM, ER120, Villejuif, France) for invaluable assistance with the implementation of the study.

\section{REFERENCES}

$1 \mathrm{Hu}$ FB. Dietary pattern analysis: a new direction in nutritional epidemiology. Curr Opin Lipidol 2002; 13: 3-9.

2 Fung TT, Hu FB, Holmes MD, et al. Dietary patterns and the risk of postmenopausal breast cancer. Int J Cancer 2005; 116: 116-121.

3 Terry P, Hu FB, Hansen H, Wolk A. Prospective study of major dietary patterns and colorectal cancer risk in women. Am J Epidemiol 2001; 154: 1143-1149.

$4 \mathrm{Hu}$ FB, Rimm EB, Stampfer MJ, Ascherio A, Spiegelman D, Willett WC. Prospective study of major dietary patterns and risk of coronary heart disease in men. Am J Clin Nutr 2000; 72: 912-921.

5 van Dam RM, Rimm EB, Willett WC, Stampfer MJ, Hu FB. Dietary patterns and risk for type 2 diabetes mellitus in US men. Ann Intern Med 2002; 136: 201-209.

6 Butler LM, Koh WP, Lee HP, Tseng M, Yu MC, London SJ. Prospective study of dietary patterns and persistent cough with phlegm among Chinese Singaporeans. Am J Respir Crit Care Med 2006; 173: 264-270.

7 Varraso R, Fung TT, Hu FB, Willett W, Camargo CA. Prospective study of dietary patterns and chronic obstructive pulmonary disease among US men. Thorax 2007; 62: 785-790.

8 Varraso R, Fung TT, Barr RG, Hu FB, Willett W, Camargo CA Jr. Prospective study of dietary patterns and chronic obstructive pulmonary disease among US women. Am J Clin Nutr 2007; 86: 488-495.

9 McKeever TM, Britton J. Diet and asthma. Am J Respir Crit Care Med 2004; 170: 725-729.

10 Romieu I. Nutrition and lung health. Int J Tuberc Lung Dis 2005; 9: 362-374.

11 Clavel-Chapelon F, van Liere MJ, Giubout C, et al. E3N, a French cohort study on cancer risk factors. E3N Group. Etude Epidémiologique auprès de femmes de l'Education Nationale. Eur J Cancer Prev 1997; 6: 473-478.

12 van Liere MJ, Lucas F, Clavel F, Slimani N, Villeminot S. Relative validity and reproducibility of a French dietary history questionnaire. Int J Epidemiol 1997; 26: Suppl. 1, S128-S136.

13 Ferris BG. Epidemiology Standardization Project (American Thoracic Society). Am Rev Respir Dis 1978; 118: 7-53.

14 Touvier M, Kesse E, Volatier JL, Clavel-Chapelon F, Boutron-Ruault MC. Dietary and cancer-related behaviors of vitamin/mineral dietary supplement users in a large cohort of French women. Eur J Nutr 2006; 45: 205-214.

15 Touvier M, Niravong M, Volatier JL, et al. Dietary patterns associated with vitamin/mineral supplement use and smoking among women of the E3N-EPIC cohort. Eur J Clin Nutr 2007; [Epub ahead of print PMID: 17882135].

16 Ainsworth BE, Haskell WL, Leon AS, et al. Compendium of physical activities: classification of energy costs of human physical activities. Med Sci Sports Exerc 1993; 25 71-80.

17 Schulze MB, Hoffmann K, Kroke A, Boeing H. Dietary patterns and their association with food and nutrient intake in the European Prospective Investigation into Cancer and Nutrition (EPIC)-Potsdam study. Br J Nutr 2001; 85: 363-373.

18 Kesse E, Clavel-Chapelon F, Boutron-Ruault MC. Dietary patterns and risk of colorectal tumors: a cohort of French women of the National Education System (E3N). Am J Epidemiol 2006; 164: 1085-1093.

19 Varraso R, Jiang R, Barr RG, Willett WC, Camargo CA Jr. Prospective study of cured meats consumption and risk of chronic obstructive pulmonary disease in men. Am J Epidemiol 2007; 166: 1438-1445.

20 Jiang R, Paik DC, Hankinson JL, Barr RG. Cured meat consumption, lung function and chronic obstructive pulmonary disease among US adults. Am J Respir Crit Care Med 2007; 175: 798-804.

21 Lopez-Garcia E, Schulze MB, Fung TT, et al. Major dietary patterns are related to plasma concentrations of markers of inflammation and endothelial dysfunction. Am J Clin Nutr 2004; 80: 1029-1035.

22 Shaheen SO, Sterne JA, Thompson RL, Songhurst CE, Margetts BM, Burney PG. Dietary antioxidants and asthma in adults: population-based case-control study. Am J Respir Crit Care Med 2001; 164: 1823-1828.

23 Sisson JH. Alcohol and airways function in health and disease. Alcohol 2007; 41: 293-307.

24 Vally $\mathrm{H}$, de Klerk N, Thompson PJ. Alcoholic drinks: important triggers for asthma. J Allergy Clin Immunol 2000; 105: 462-467.

25 Siroux V, Kauffmann F, Pison C, Pin I. Caractère multidimensionnel de la sévérité de l'asthme dans l'enquête EGEA. [Multidimensional character of asthma severity in the EGEA study.] Rev Mal Respir 2004; 21: 917-924.

26 Anon. A plea to abandon asthma as a disease concept. Lancet 2006; 368: 705.

27 Sunyer J, Pekkanen J, Garcia-Esteban R, et al. Asthma score: predictive ability and risk factors. Allergy 2007; 62: 142-148.

28 Bouzigon E, Siroux V, Dizier MH, et al. Scores of asthma and asthma severity reveal new regions of linkage in EGEA study families. Eur Respir J 2007; 30: 253-259.

29 Global Initiative for Asthma. Global Strategy for Asthma Management and Prevention. Bethesda, National Heart, Lung and Blood Institute, National Institutes of Health, 1995 (updated 2006). NIH publication no. 95-3659.

30 Taylor DR, Bateman ED, Boulet LP, et al. A new perspective on concepts of asthma severity and control. Eur Respir J 2008; 32: 545-554.

31 Willett WC. Recall of remote diet. In: Willett WC, ed. Nutritional Epidemiology. New York, Oxford University Press, 1998; pp. 148-156.

32 Fung TT, Rimm EB, Spiegelman D, Rifai N, Tofler GH, Willett WC, Hu FB. Association between dietary patterns and plasma biomarkers of obesity and cardiovascular disease risk. Am J Clin Nutr 2001; 73: 61-67. 